\title{
Pathways to STEM: Understanding identity of adult physicists through narrative analysis
}

\author{
Simone Hyater-Adams ${ }^{1}$, Kathleen Hinko ${ }^{2}$ and Noah Finkelstein ${ }^{2}$ \\ ${ }^{1}$ ATLAS Institute, University of Colorado Boulder, Boulder, CO 80309 \\ ${ }^{2}$ Department of Physics, University of Colorado Boulder, Boulder, CO 80309
}

\begin{abstract}
In order to characterize how individuals make sense of their physics and racial identities and intersections of these identities, four university graduate students were interviewed about their own pathways into the field. To analyze these interviews, we utilize a narrative inquiry process combined with Nasir's (2011) framework of racialized identity resources. These interviews are analyzed in a two-step process: 1) to understand how participants make sense of their journey into physics, and 2) to investigate how their stories connect to race and gender. We find that the way these graduates talk about their pathways draws from common discourses around race and gender in STEM and provides information about what resources were most influential along their way.
\end{abstract}

PACS: $01.40 . \mathrm{Fk} ; 01.30 . \mathrm{Cc}$

\section{INTRODUCTION}

There is a paucity of research on the connection between a person's identity as a doer of science and their racial identity, especially for groups underrepresented in the STEM fields. Our broader research efforts seek to examine the ways that identity is formed and made sense of by physics students and how students negotiate these identities within the scope of their racial backgrounds. We situate our efforts in the context of informal physics programming. Many physics departments have "outreach" efforts that aim to increase the interest and exposure of youth from underrepresented groups in physics. However, the demographics of the physics community at large (and often the purveyors of the physics outreach) are overwhelmingly white and male, and can have gender and racial backgrounds that are dissimilar from the backgrounds of the target audience. In general, researchers have looked at how informal science can affect marginalized groups in physics separately from how these marginalized groups experience the culture of physics.

In this work, we report on results of a pilot study designed to examine the pathways into physics of university physics students of different racial backgrounds who volunteer in an informal physics program. We analyze interviews of University Educators (UEs), who are, graduate students in the University of Colorado Physics Department that participate in the PISEC afterschool program [1]. PISEC UEs work with K-8 children afterschool on physics activities designed to advance children's interest, identity, and capacity in STEM while simultaneously engaging university physicists and physics students in community-based programs and developing their educational identities and commitments. We utilize our easy access to this population in order to create a sample of four students (two white women, one white man, and one black man) to conduct this pilot study.
UEs have already made the decision to pursue and persist in the field of physics; therefore, in this work, we utilize this selection bias, as it provides a valuable perspective about what it takes for an individual to pursue a degree and develop an identity in physics. By analyzing these interviews from a perspective of narrative inquiry [2], as well as interpreting results using Nasir's [3] framework for racialized identity resources, we look to answer the following research questions:

- What were the UEs' stories about the relationship between their past experiences and physics careers?

-What do these stories, and the way they tell these stories, portray about their physics and racial identities?

- How do they draw on broader discourses around gender and race in STEM?

\section{BACKGROUND}

In this project, we use a lens of identity to understand how the UEs in PISEC make sense of their paths into physics. The ultimate goal is to understand how students negotiate their identities as physicists with their racial identities, with this study being a first step to the larger picture. Researchers have looked at racial identity and physics identity separately, but only a few have conducted studies about how these identities overlap. Carlone et al. [4] studied experiences of women of color in STEM by using a model for science identity that included three components: performance, competence, and recognition. The results of their studies showed that the most impactful components of this model were competence and recognition. Hazari and Sonnert have used Carlone's work to construct a more specific framework for physics identity that also explicitly includes interest [5].

Nasir's work provides a (non-STEM specific) model to examine racialized identity through the availability of resources in different learning environments [3]. The components of this framework include ideational, material, 
and relational resources. Ideational resources are defined as ideas about oneself and one's relationship to and place in a practice and the world, as well as ideas about what is valued and what is good. Material resources are the ways physical environments, their organization, and the artifacts in them support one's sense of connection to a practice. Relational resources are defined as the way in which positive relationships with others in the context can increase one's connection to a practice. Additionally, the concepts of whiteness [8] and stereotypic attribution bias [9] connect to Nasir's framework and to broader discourses around race and gender in STEM. The concept of whiteness can be defined as a system of privilege and can manifest in education through ideas of colorblindness [8]. Through the inability to recognize structural obstacles of students of color, whiteness functions as unacknowledged privilege. Stereotype Attribution considers one's perception of relationship to a broader stereotyped group. This concept is used to document how women in STEM attribute their success to external conditions rather than innate ability [9].

In parallel, we draw on the methods of Ong, who studied women of color in physics and found that the culture of the field requires women of color to constantly grapple with their cultural, gender, and physics identities [6]. Ong characterizes physics culture as specifically unwelcoming for women of color, and she gives suggestions on ways to tackle this issue. Ong's work utilizes the method of understanding racial identities in science through subjects' personal narratives, or narrative inquiry. As an analytical tool, narrative inquiry is premised on the idea that we as humans understand and give meaning to our lives through story. Analyzing narratives examines intention as well as language, asking the questions: why are the events configured this way, and what cultural resources does the story draw on or take for granted [7]?

This methodology is recognized as a useful tool for qualitative studies [2]; we use this approach in our work as detailed in Sections 3 and 4. By focusing on the stories that UEs tell, we use the structure of narrative inquiry analysis as a tool of applying Nasir's framework. The lens of identity provided by the racialized identity resources model gives a way to pull meaning from the narratives around which students currently find themselves in the field of physics and why.

\section{METHODS}

This project focuses on four UEs who are all currently pursuing graduate degrees in physics. Each UE was individually interviewed and recorded about their background as well as their experiences in the PISEC program. During the interviews, subjects were asked to talk about how they came to study physics. Interviews ranged from 15 to 40 minutes in length. For some of the participants, this question prompted stories dating back to infanthood, while others focused on school experiences alone.

From their stories, connections were noticeable between the way UEs made meaning of their experiences and the effect these experiences had on landing them in the physics field. For analysis, excerpts were drawn from the full-length interviews of the UEs that focused specifically on their past narratives. We performed two levels of analysis on these excerpts: The first level of analysis was focused on classifying the identity resources (described in Nasir's framework) that UEs explicitly discussed in their stories. The second level of analysis examined the ways in which the UEs discussed these resources, highlighting moments where their language took certain resources for granted. Each narrative excerpt was coded for explicit discussion of the three identity resources: material, relational, and ideational. Then they were coded again for places where one or more of these resources were discarded in some form by the way that the UEs either framed it, or the language they used to describe it. In the following sections, the findings from this two-part analysis are discussed.

\section{PRELIMINARY FINDINGS}

From the first stage of our analysis, we document similarities and differences in resources being discussed amongst the four UEs. Table 1 shows excerpts from the interviews along with the different resources discussed within them. We find that all of the students referenced experiences that can be linked to at least two of Nasir's identity resources. For example, Laura talks about her high school physics experience, attributing her interest in the field solely to a high school teacher and physics class, giving value to the relational resource between her and her teacher, as well as describing material and ideational resources from class activities, i.e. describing the field trip to an amusement park as making physics relatable. Mary speaks to all three types of resources in her narrative, describing how a TV show with a female physicist sparked her interest in physics (ideational) and stating that her grandfather was a physicist (relational) who would do science experiments with her (material). Alex talked about his journey from studying history to physics, explaining that his drive came from his hate for writing. His story suggests material and ideational resources influenced him when describing how his past "predisposed" him for science, even though he was not initially interested in the field. Joe's description clearly reflects material and relational influences from his mother and the fellowship program he got involved with early on in his undergraduate career. These narratives each show a direct connection to identity development.

From the consolidation of the resources each UE discussed in their stories, two small trends are noticeable. The first is that every UE discussed a resource that can be considered a material resource by Nasir's definitions. 
TABLE 1. Transcript and coding on narrative content. "I" refers to the interviewer.

\begin{tabular}{|c|c|c|}
\hline $\mathbf{U E}$ & Resourc & Excerpt \\
\hline $\begin{array}{l}\text { Laura } \\
\text { (white } \\
\text { woman) }\end{array}$ & $\begin{array}{l}\text { Relational } \\
\text { Ideational } \\
\text { Material }\end{array}$ & $\begin{array}{l}\text { L: Uhm, it was like a physics teacher in high school, that teacher was the only reason I took physics in } \\
\text { the first place. So it was mostly in high school but for that class we had our final at like an amusement } \\
\text { park and we rode on all the rides and took measurements and it was really cool because it made physics } \\
\text { like super relatable... and then I just couldn't stop thinking about physics after that class. } \\
\text { K: Yeah.. I probably would've never taken a physics class if it weren't for that teacher. } \\
\text { I: So were you not into science when you were younger? } \\
\text { K: Not really, no... I didn't really have like the opportunity to do sciency things } \\
\text { I: mmm why? What was that caused } \\
\text { K: Uhm a lack of me being outgoing, but like I don't remember school doing any cool science stuff and } \\
\text { being involved with anything like that }\end{array}$ \\
\hline $\begin{array}{l}\text { Mary } \\
\text { (white } \\
\text { woman) }\end{array}$ & $\begin{array}{l}\text { Relational } \\
\text { Ideational } \\
\text { Material }\end{array}$ & $\begin{array}{l}\text { J: Uhmm, yeah it's actually kind of a stupid story *laughs*. Uhh I got really into a sci fi show, called } \\
\text { Stargate and it had this uhm really awesome physicist chick and I was like "Aww this is cool!" and } \\
\text { there was just enough like actual physics that. I got into it and somehow was like yeah I should do this } \\
\text { for a career." } \\
\text { I: how old were you when that happened? } \\
\text { J: I was } 14 \text { ?... actually I wanted to be a fighter pilot first and then found out that I couldn't because of } \\
\text { my glasses, and then physics was my second choice. *laughing* } \\
\text { I: } 14 \text { ? Did you have any experiences younger than } 14 \text { where you kind of realized you liked science or } \\
\text { anything? } \\
\text { J: Well I always liked science. My grandpa was physicist so we would do like stupid little science } \\
\text { experiments sometimes.. but not really, not a ton. }\end{array}$ \\
\hline $\begin{array}{l}\text { Alex } \\
\text { (white } \\
\text { man) }\end{array}$ & $\begin{array}{l}\text { Ideational } \\
\text { Material }\end{array}$ & $\begin{array}{l}\text { C: Uhm, great question.. uhm I ended up in physics because I got to college and realized that I didn't } \\
\text { like writing papers. ....but paper writing is so subjective it's kind of hard to like, you've gotta read what } \\
\text { your professor wants and you've have to form opinions and they kind of like sync them. So I thought } \\
\text { about math and then I also thought well physics is just like math but it's more applicable and probably } \\
\text { easier for me to get a job, and so I picked physics. And I, you know, that's sort of a simplified thing } \\
\text { because in like high school I took science classes and I really liked them and when I was a little kid I } \\
\text { was like you know, had the little tinkering aspect to it, so I think definitely my brains a little sort of } \\
\text { wired--predisposed, to that sort of thing. }\end{array}$ \\
\hline $\begin{array}{l}\text { Joe } \\
\text { (black } \\
\text { man) }\end{array}$ & $\begin{array}{l}\text { Relational } \\
\text { Material }\end{array}$ & $\begin{array}{l}\text { G: Uhm, guess first I wanted to be a math teacher in my freshman year, but my mom was suggesting I } \\
\text { do something more useful and something that's more helpful to other people also more pay so she said I } \\
\text { should be an engineer. ...Uhm also at the time, I ended up running into this scholarship that was } \\
\text { emailed to me, LSAMP, which allowed minority students in sciences to apply for the scholarship, but at } \\
\text { first I didn't know it was a fellowship I thought it was a scholarship, but a year later after the first } \\
\text { meeting I found out it was a fellowship that helped minority students get into PhD programs, so I said } \\
\text { "you know what it would be cool to be a professor" you know and maybe I should go for it. And I } \\
\text { learned more about how to get a PhD path like research, within the institution and also summer research } \\
\text { and eventually after going through the program part of the requirements was for us to apply to a } \\
\text { minimum of } 5 \text { PhD programs } 2 \text { masters and } 1 \text { post-bac program and amongst the } 11 \text { schools I applied to } \\
\text { I got into CU Boulder and I'm here now. }\end{array}$ \\
\hline
\end{tabular}

Their similarities in personal narrative suggest that these relational resources may be influential for students from groups underrepresented in physics. The second level of analysis focused on the language each UE used to describe his/her journey into the field, in order to understand the way they give meaning to these resources. There were two different trends in this data that pointed to broader discourses around whiteness (Table 2) and gender (Table 3). The stories told by Alex and Mary reflects discourses around whiteness [8]. From the two examples shown, both
Alex and Mary display a sense of omission of certain resources mentioned in their stories. Alex talks about choosing physics as a Plan B to his original career choice of history. He neglects, however, to acknowledge the ideational resource that is his inherent confidence in his ability to switch to physics. This omission speaks to the structures of whiteness that allow the idea of physics to seem more accessible to privileged groups. Mary's statement about her grandfather's relationship not being a big influence on her trajectory into physics shows similar 
neglect. Her inability to recognize the relational resource speaks to the naturalization of privileges through whiteness.

The stories told by Laura and Mary reflects discourses around stereotypic attribution bias [9]. From the two examples shown, both Laura and Mary display a sense of discredit to certain resources and the cause of their access to them. Laura talks about her engagement in science activities as a child, attributing her limited access to these material resources as her own fault, due to a "lack of [her] being outgoing". Mary begins her story of idolizing a female physicist character on a popular TV show by premising it with the statement "it's actually kind of a stupid story". Her language discredits what she implies as a very influential ideational resource, giving less meaning to what caused her inspiration.

The trends that emerged from this two-part analysis show that there is much to learn about the differences in experiences of physics students. By examining the narratives of these UEs experiences in this analytic way, we can construct broad understandings of the ways that students in physics make sense of the resources that lead them to the field. This understanding pulls from the broader discourses around race and gender in STEM fields, and the experiences that students from underrepresented groups in physics tend to have.

\section{SIGNIFICANCE}

Societal and cultural structures provide youth different opportunities and resources based on their race, causing students from different backgrounds to understand the resources being provided to them differently [10]. Because of this, understanding these trends can help better quantify the experiences of certain groups, and in turn help develop knowledge around ways to better serve students from underrepresented groups through informal science education.

Through this examination, useful information can be extracted for PISEC, and other educational programs that have a similar mission [11]. By understanding the stories of students already in the field, we can better understand what aspects of our educational programs can be more impactful to the building of this identity. Through the cases presented here, we have begun to develop ideas around ways to create environments to provide access to those resources that are most influential for the students we are trying to engage (underrepresented minorities). We can also begin to

[1] K. Hinko, et al., PRST-PER (to appear).

[2] C. McMullen \& I. Braithwaite, J Bus Rsrch Meth, 2013, pp 92-91.

[3] N. Nasir, Racialized identities. Stan. U.Press, 2011.

[4] H. Carlone \& A. Johnson, J..Res.Sci.. Teach..,2007 pp. $1187-$ 1218.

[5] Z. Hazari and G. Sonnert,. J. of Res. in Sci. Teach., 2009.

[6] M. Ong, Harvard U.. Soc.Prob., 2005, pp. 593-617. understand how whiteness influences perceptions about the accessibility of the field, and how we can manage these perceptions amongst our majority white volunteers as well as the roles that gender attribution biases play in the construction of identity. Armed with this information, we can work to avoid perpetuating these stereotypes within the program. We plan continue this work by conducting a larger study similar to this on all UEs that participate in PISEC for the 2015/2016 academic year.

\section{ACKNOWLEDGMENTS}

This work is supported by the JILA NSF Physics Frontier Center, NSF DRL-AISL \#1423496 and the CU Boulder ATLAS Institute.

TABLE 2. Coding narrative language around whiteness.

\begin{tabular}{|l|l|}
\hline Construct & Whiteness as a racial discourse [8] \\
\hline Excerpts & $\begin{array}{l}\text { A: I ended up in physics because I got to } \\
\text { college and realized that I didn't like writing } \\
\text { papers }\end{array}$ \\
\cline { 2 - 2 } & $\begin{array}{l}\text { M: Well I always liked science. My grandpa } \\
\text { was a physicist so we would do like stupid } \\
\text { little science experiments sometimes...but not } \\
\text { really, not a ton. }\end{array}$ \\
\hline $\begin{array}{l}\text { Resources } \\
\text { taken for } \\
\text { granted }\end{array}$ & $\begin{array}{l}\text { A: Ideational Resources } \\
\text { M: Relational Resources }\end{array}$ \\
\hline
\end{tabular}

TABLE 3. Coding narrative language around gender.

\begin{tabular}{|l|l|}
\hline Construct & Stereotypic Attribution Bias [9] \\
\hline Excerpts & $\begin{array}{l}\text { L: I didn't really have like the opportunity to do } \\
\text { sciency things (due to) a lack of me being } \\
\text { outgoing, but like I don't remember school } \\
\text { doing any cool science stuff and being involved } \\
\text { with anything like that. }\end{array}$ \\
\cline { 2 - 3 } & $\begin{array}{l}\text { M: Yeah it's actually kind of a stupid story } \\
\text { *laughs*. I got really into a sci-fi show, called } \\
\text { Stargate and it had this really awesome } \\
\text { physicist chick and I was like "This is cool!" } \\
\text { and there was just enough like actual physics } \\
\text { that ... I got into it and somehow was like yeah } \\
\text { I should do this for a career. }\end{array}$ \\
\hline $\begin{array}{l}\text { Resources } \\
\text { discredited }\end{array}$ & $\begin{array}{l}\text { L: Material Resources } \\
\text { M: Ideational Resources }\end{array}$ \\
\hline
\end{tabular}

[7] S.M. Ospina and J. Dodge, Pub. Adm. Rev., 2005, pp. 143157.

[8] Z. Leonardo, Race Ethn. \& Ed. 10.3, 2007, pp.261-278.

[9] D. Sekaquaptewa, Discounting Their Own Success, 2011, pp.291-295.

[10] D. Martin, in N.S. Nasir, Improving Access to Mathematics, Teach. Coll. Press, 2006, pp.147-157.

[11] Com. on Prosp. in the Global Economy, NAS, March 2007. 